\title{
openheart Web-based cardiac REhabilitatioN alternative for those declining or dropping out of conventional rehabilitation: results of the WREN feasibility randomised controlled trial
}

\author{
Linzy Houchen-Wolloff, ${ }^{1}$ Nikki Gardiner, ${ }^{1}$ Reena Devi, ${ }^{2}$ Noelle Robertson, ${ }^{3}$ \\ Kate Jolly, ${ }^{4}$ Tom Marshall, ${ }^{4}$ Gill Furze, ${ }^{5}$ Patrick Doherty, ${ }^{6}$ Ala Szczepura, ${ }^{7}$ \\ John Powell, ${ }^{8}$ Sally Singh ${ }^{1,9}$
}

To cite: Houchen-Wolloff $L$, Gardiner N, Devi R, et al. Webbased cardiac REhabilitatioN alternative for those declining or dropping out of conventional rehabilitation: results of the WREN feasibility randomised controlled trial. Open Heart 2018;5:e000860. doi:10.1136/ openhrt-2018-000860

Received 23 May 2018 Revised 2 August 2018 Accepted 14 August 2018
Check for updates

(c) Author(s) (or their employer(s)) 2018. Re-use permitted under CC BY. Published by BMJ.

For numbered affiliations see end of article.

Correspondence to Dr Linzy Houchen-Wolloff; Linzy. Houchen@uhl-tr.nhs.uk

\section{ABSTRACT}

Introduction Cardiac rehabilitation (CR) is typically delivered in hospital-based classes and is recommended to help people reduce their risk of further cardiac events. However, many eligible people are not completing the programme. This study aimed to assess the feasibility of delivering a web-based CR intervention for those who decline/drop out from usual CR.

Intervention A web-based CR programme for 6 months, facilitated with remote support.

Methods Two-centre, randomised controlled feasibility trial. Patients were randomly allocated to web-based CR/ usual care for 6 months. Data were collected to inform the design of a larger study: recruitment rates, quality of life (MacNew), exercise capacity (incremental shuttle walk test) and mood (Hospital Anxiety and Depression Scale). Feasibility of health utility collection was also evaluated. Results 60 patients were randomised $(90 \%$ male, mean age $62 \pm 9$ years, $26 \%$ of those eligible). $82 \%$ completed all three assessment visits. $78 \%$ of the web group completed the programme. Quality of life improved in the web group by a clinically meaningful amount $(0.5 \pm 1.1$ units vs $0.2 \pm 0.7$ units: control). Exercise capacity improved in both groups but mood did not change in either group. It was feasible to collect health utility data.

Conclusions It was feasible to recruit and retention to the end of the study was good. The web group reported important improvements in quality of life. This intervention has the opportunity to increase access to $\mathrm{CR}$ for patients who would otherwise not attend. Promising outcomes and recruitment suggest feasibility for a full-scale trial.

Trial registration number 10726798 .

\section{INTRODUCTION}

Coronary heart disease (CHD) affects over 2.3 million people in the UK. ${ }^{1}$ There is a very large cost to both the individual, in terms of loss of quality of life, and to society, in terms of healthcare costs and loss of productivity. It has been estimated that the cumulative cost

\section{Key questions}

What is already known about this subject?

- Cardiac rehabilitation (CR) is effective in improving patient outcomes and reducing the risk of future cardiac events.

- Despite being recommended in national guidelines, approximately $50 \%$ of eligible patients do not take part or do not complete a programme.

What does this study add?

- The web-based programme offers an alternative way to complete CR in those who decline or drop out of a conventional hospital programme.

- The wed-based alternative was feasible to deliver and promising signals were noted in secondary outcomes.

How might this impact on clinical practice?

- We believe that this web-based approach could provide an acceptable way to increase the provision of CR for those unable (or unwilling) to attend conventional programmes; or to be an alternative mode of CR delivery in a full, choice-based CR menu.

- In turn, this could reduce the risk of future cardiac events in those able to attend a programme.

of cardiovascular disease (CVD) to the UK economy is in the region of $£ 30$ billion annually, ${ }^{2}$ through direct service provision, lost productivity and informal care. ${ }^{3}$ The acute and ongoing management of individuals with CHD has been outlined in many national and international guidelines, ${ }^{4}$ and acknowledges the importance of cardiac rehabilitation (CR) in the care pathway of these individuals. CR is commonly a structured and supervised package of care that supports individuals with CHD to achieve their best possible levels of physical, psychological and social function. ${ }^{5-7}$ 
Many national and international guidelines on management of CHD acknowledge the importance of CR in the care pathway, including the National Institute for Health and Care Excellence (NICE) clinical guideline 172 on myocardial infarction (MI), ${ }^{8} 94$ on unstable angina and non-ST segment elevation $\mathrm{MI}^{9}$ and guideline 108 on chronic heart failure. ${ }^{10}$ The CVD outcomes strategy (2013) set an ambitious target for $65 \%$ of people discharged from hospital with a primary diagnosis of acute MI or a surgical revascularisation to be offered $\mathrm{CR}^{11}$

Despite national guidance, the most recent National Audit of Cardiac Rehabilitation indicates that only $51 \%$ of eligible patients actually receive CR. ${ }^{12}$ There also appears to be unacceptable variation in uptake (30\%-90\%) across the UK, underpinned by complex reasons; some related to the organisation and system of delivery ${ }^{13}$ and others to patients' individual choice. Factors related to rehabilitation non-attendance that have been identified comprised employment commitments, difficulties with transport, lack of time, distance to travel to rehabilitation and embarrassment related to attending rehabilitation. ${ }^{14-16}$ There appears to be some consensus around barriers that argue for the development of alternative formats and modes of rehabilitation delivery, so that access is broadened. ${ }^{17}$ Currently within practice, the "Heart Manual' 18 and the 'Angina Plan'19 are alternative paper-based home rehabilitation options, but are not widely delivered. Studies have shown that most patients with CHD who are still working would prefer a home-based CR programme. ${ }^{20}$ Interestingly, CR delivered either as a supervised or facilitated self-delivered programme has equivalent positive outcomes. ${ }^{21}$ The audit also identified that $33 \%$ of patients do not complete a CR programme and the most cited reason for attrition or failure to complete group-based $\mathrm{CR}$ is the need to have 'return to work'. ${ }^{12}$

There is considerable interest in digital health as a means of delivering healthcare for individuals with long-term conditions, where a standard intervention is delivered in a way that is not geographically or time constrained. An increasing proportion of retired people are using the internet, reflecting the typical rehabilitation population. In the UK, $79 \%$ and $76 \%$ of men and women aged between 65 and 74 years respectively had used the internet within the previous 3 months. ${ }^{22}$ Among adults aged $75+$ years, internet use increased from $19.9 \%$ to $40.5 \%$ from 2011 to 2017 (ie, $3 \%$ a year). ${ }^{22}$

Studies carried out across Europe and North America have investigated the efficacy of web-based interventions for those with heart disease. ${ }^{23-26}$ The largest was reported in $2012^{26}$; however, it was not a comprehensive rehabilitation programme (as defined by the Department of Health's commissioning pack ${ }^{27}$ and recruited participants with a broad range of CVDs). Reid $e t a l^{4}$ reported on a Canadian study which recruited exclusively people postprimary percutaneous coronary revascularisation (percutaneous coronary intervention (PCI) or angioplasty) who were offered a physical activity intervention that was web based. The paper reported a benefit in the intervention arm not observed in the control arm, suggesting the potential value of web-based interventions in this population. The Cochrane review of internet-based interventions for the secondary prevention of CHD, published in 2015 , suggested that there was some evidence to support improvements in health-related quality of life and behaviour change, but there was insufficient evidence to draw firm conclusions. ${ }^{28}$

The University Hospitals of Leicester (UHL) NHS Trust has developed a web-based CR programme ('ACTIVATE YOUR HEART', www.activateyourheart.org.uk). This online programme was developed over a number of years, and has been tested in two small studies. The first was a pilot randomised controlled trial (RCT) in patients with angina managed exclusively in primary care. ${ }^{29}$ Encouragingly, the data demonstrated improvements in angina symptoms, objectively measured physical activity and levels of anxiety and depression, compared with the control group. A second single cohort observational study collected pilot data from patients attending CR at UHL, which identified significant improvements $(p<0.05)$ in depression, exercise capacity and quality of life $(n=106)$. Interestingly $65 \%$ of patients reported that they would not otherwise have attended CR. ${ }^{30}$ This has formed the basis of a case study on the NICE website (http://www. nice.org.uk/usingguidance/sharedlearningimplementi ngniceguidance/examplesofimplementation/eximpresults.jsp?o=718), encouraging the use and exploration of alternative forms of delivery.

The use of the internet permits greater flexibility of CR delivery, as patients are able to complete their programme at a place and time that suit them. It is also capable of reaching a wider population, especially those patients who live in rural areas. ${ }^{31}$ Studies have highlighted how web-based interventions can also help improve knowledge for patients with chronic health conditions. ${ }^{32}$ There may also be benefits to the service, releasing capacity for CR specialists to manage more complex patients in conventional hospital classes, as well as providing additional choice for those unwilling to do standard CR. ${ }^{33}$

\section{OBJECTIVES}

The study aimed to assess the feasibility of delivering a trial offering an alternative web-based CR intervention for those who decline or drop out from conventional supervised CR. The study was a two-centre feasibility study, collecting quantitative data to inform the design of a definitive clinical trial. The specific objectives were to:

1. Derive an estimate of the number of eligible patients at participating centres.

2. Assess the willingness of patients to be randomised to this study and a future trial.

3. Determine opportunities and methods to recruit patients to a future trial.

4. Determine participant adherence to the web-based rehabilitation programme. 
5. Test methods for the collection of baseline and follow-up clinical data as well as data completeness and accuracy.

6. Assess the willingness of participants to allow researchers to follow their hospital records/health service data.

7. Identify methods to measure economic costs (health and social care resource use and patientborne costs) and outcomes (including health utility and return to normal work or other activity).

We also collected qualitative data in the form of staff and patient interviews (this will be reported in a separate paper).

\section{METHODS \\ Design}

A feasibility study to inform the design of a definitive RCT. Patients were randomised to either best usual care or the web-based programme ("ACTIVATE YOUR HEART') from two CR centres in the UK (UHL NHS Trust (acute) and Lincolnshire Community Health Services NHS Trust (community)). The trial is registered on the ISRCTN website (ref: 10726798). We aimed to recruit people who declined, or were unable to take up or dropped out of conventional rehabilitation. These participants were recruited from different stages of the rehabilitation pathway, including those identified from the CR database, or those declining the offer of rehabilitation at the time of the initial assessment prior to enrolment onto a conventional programme. Outcome measures were collected at baseline, 8 weeks and 6 months.

\section{Participants}

Inclusion criteria

- Confirmed primary diagnosis of CHD (including angina, post-MI, post-PCI).

- Eligible for conventional CR (eligibility as described in guidance from the British Association for Cardiovascular Prevention and Rehabilitation-updated 2017). ${ }^{34}$

- Access to, familiarity with and ability to use the internet. Questions were asked to establish familiarity with the internet, for example, use of either online shopping/online banking.

- People who have recently ( $<12$ months) declined, or were unable to take up the invitation of rehabilitation. These people are defined as those expressing an unwillingness to attend any further stages of the programme either at patient assessment or when the patient care plan was developed.

- People who have recently ( $<12$ months) 'dropped out' of rehabilitation. These people are defined as those not attending two consecutive sessions of the comprehensive rehabilitation programme.

\section{Exclusion criteria}

- No access to the internet, unfamiliar with or unable to use the internet.
- Individuals who have completed rehabilitation for a previous admission in the last 12 months.

- Those demonstrating high levels of depression (defined by baseline Hospital Anxiety and Depression Scale (HADS) score ${ }^{35}>11$ (moderate depression)) and poor exercise capacity (defined by poor performance on the incremental shuttle walking test (ISWT) ${ }^{36}$ level achieved <3-equivalent to walking $120 \mathrm{~m})$.

- Unable to read English (as the intervention is currently only available in English).

\section{Randomisation}

Participants were randomised into one of two groups: the intervention group (web-based CR programme) and the control group (usual care) using a web-based randomisation system (www.sealedenvelope.com). Randomisation was stratified by centre, 30 patients by site, 60 in total. Randomisation was performed using permuted blocks, with $60 \%$ to the intervention and $40 \%$ to the control group. Unequal randomisation was performed to allow for more experience with the intervention group and more data (power) in this group to detect adverse events.

\section{Trial interventions}

Intervention group: web-based CR programme

'ACTIVATE YOUR HEART' (www.activateyourheart.org. uk) is an online intervention designed for participants to use self-directed at home, facilitated with remote support from the CR team. The broad aim of the programme is to improve the overall cardiac risk factor profile of patients. The intervention is an interactive, password-protected, tailored CR programme, contained in a website. The programme was developed at the UHL NHS Trust and coproduced with healthcare professionals, a software development team (HARK2) and a group of patients/ members of the public.

The programme contains four stages and can be completed in 8 weeks but access to the site and its features continues for 12 months. Before beginning the programme each patient receives face-to-face training on the website and a written user manual. They then complete an online registration form, providing information about their current and previous medical history and their cardiac risk factors. The website uses this information as baseline measurement, and to create an individually tailored plan for the patient. Throughout the programme, patients have access to a discussion forum and an 'ask the expert' email facility. CR staff at both centres had access to the administration side of the website; here they are able to monitor each participant's progress. Participants and the CR team were alerted whenever the programme was not being used regularly. More details about the programme are reported in a previous paper. ${ }^{30}$

\section{Control group}

Participants in this group received best usual care for their region. Usual care in the absence of CR would 
comprise a referral back to general practice and general advice in the form of standard verbal advice and guidance booklets. All participants in the control group were given the opportunity to participate in the 'ACTIVATE YOUR HEART' programme following their 6-month follow-up appointment.

\section{Outcome measures}

The primary outcome measure in this study was to assess the feasibility of recruiting/retaining people who met the inclusion criteria; those who have declined/dropped out of traditional CR.

We also examined the:

- Safety of the trial (adverse event reporting and angina symptom diary).

- Feasibility of our randomisation process and willingness to be randomised.

- Retention rate of participants to the study at 8 weeks and 6 months of follow-up.

- Feasibility of conducting the outcome measures which are proposed for a definitive trial, collected at blinded 8-week and 6-month assessments including:

- Health-related quality of life: the MacNew Heart Disease Questionnaire, ${ }^{37}$ measuring physical, emotional and social aspects of quality of life.

- Exercise capacity: measured using the ISWT, ${ }^{36}$ which is a test used to assess cardiorespiratory fitness. An initial practice test was conducted at baseline to minimise any possible learning effect.

- Anxiety and depression: measured using the HADS. $^{35}$

- Self-efficacy: measured using 'the general self-efficacy scale. ${ }^{38}$

- Resource use (health/social care and personal costs) questionnaire for healthcare and other services received: to identify methods to measure costs (health and social care resource use and patient borne costs) and outcomes (including health utility and return to normal work or other activity). The questionnaire was devised for the purposes of this study by one of the authors (AS) and can be found here: http://www.dirum.org/instruments/ details/104.

\section{Non-clinical study outcomes/process measures}

- Web usage: total web usage statistics for patients assigned to the web-based programme were monitored, along with emails sent to the expert CR team.

- Intervention completion rates among intervention group participants.

\section{Sample size estimation and recruitment target}

As this was a feasibility study, a formal sample size calculation was not required to detect between-group changes. We therefore aimed to recruit 30 individuals at each site within the recruitment phase of the study, 60 individuals in total. This was a conservative number, anticipating that each site will recruit approximately three participants per month. Data from 60 participants were deemed reasonable to assess the recruitment/retention rate and allow for planning the subsequent final trial by obtaining estimates of potential outcomes (ie, health-related quality of life) with sufficient precision (ie, with an SE of less than $8 \%$ for estimated proportions). This is in keeping with recommendations of 30 participants required in feasibility/pilot studies to estimate a parameter. ${ }^{39}$ Furthermore, a recent audit of UK feasibility studies found that the median sample size for a two-arm trial was 36 and 30 per arm, respectively, for dichotomous and continuous endpoints. ${ }^{40}$

\section{Quantitative data analysis}

Data were entered and stored on a secure web-based system (REDCAP) which has discrepancy management features. Data were then transferred from REDCAP to the Statistical Package for the Social Sciences (SPSS) V.18 (SPSS). Analysis was primarily descriptive, that is, estimation of means and SDs, proportion of patients eligible/ willing to participate in the study, dropouts and completion rates. In line with the accepted practice for feasibility studies, no $\mathrm{p}$ (significance) values/inferential statistics are presented.

\section{RESULTS}

Sixty patients were recruited and randomised to the study between December 2015 and April 2017: 37 to the web group and 23 to the control group. Figure 1 shows the

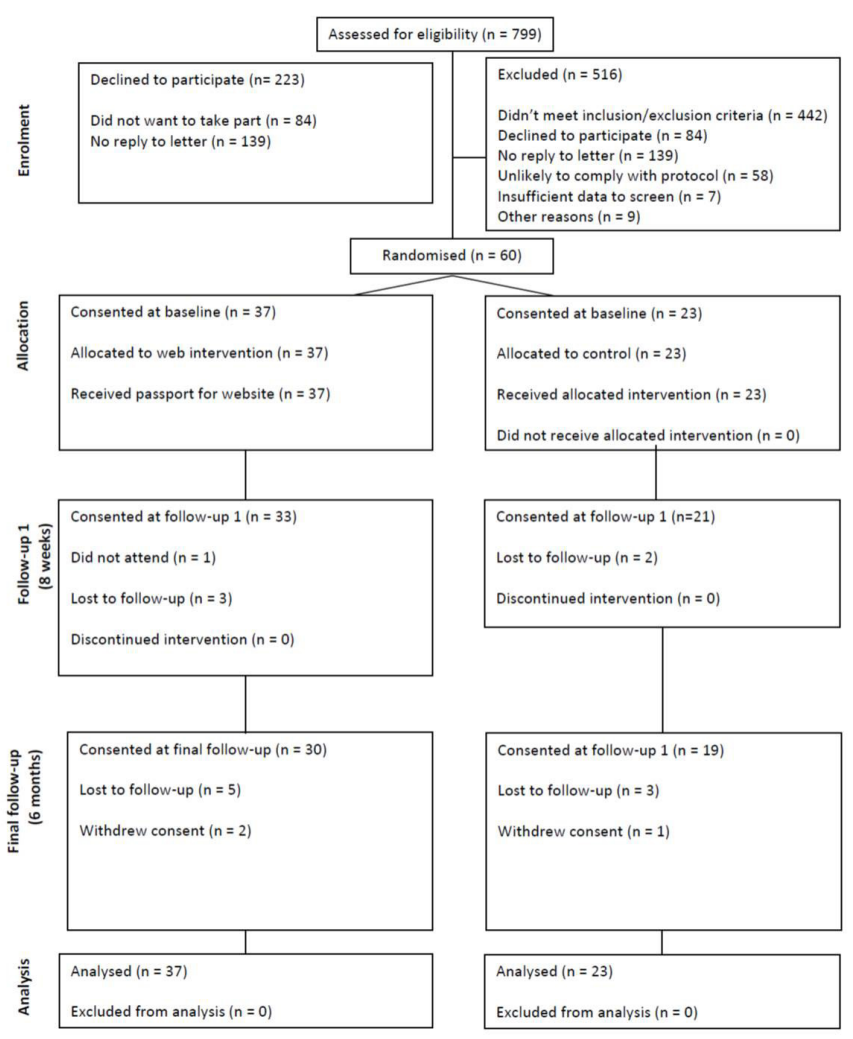

Figure 1 Consolidated Standards of Reporting Trials (CONSORT) diagram by treatment group. 


\begin{tabular}{|c|c|c|}
\hline & $\begin{array}{l}\text { Web group } \\
(n=37)\end{array}$ & $\begin{array}{l}\text { Control group } \\
(n=23)\end{array}$ \\
\hline \multicolumn{3}{|l|}{ Gender } \\
\hline Male, n (\%) & $33(89)$ & $21(9)$ \\
\hline \multicolumn{3}{|l|}{ Age } \\
\hline Mean (SD) & $62(10)$ & $61(8)$ \\
\hline \multicolumn{3}{|l|}{ Ethnicity } \\
\hline White, n (\%) & $37(100)$ & $21(91)$ \\
\hline \multicolumn{3}{|l|}{ Marital status } \\
\hline Married, n (\%) & $27(75)$ & $17(74)$ \\
\hline \multicolumn{3}{|l|}{$\mathrm{BMI}$} \\
\hline Mean (SD) & $28(11)$ & $29(12)$ \\
\hline \multicolumn{3}{|l|}{ Family history } \\
\hline Yes, $\mathrm{n}(\%)$ & $20(54)$ & $6(26)$ \\
\hline \multicolumn{3}{|l|}{ Employment status, n (\%) } \\
\hline Employed & $14(38)$ & $9(39)$ \\
\hline Self-employed & $1(3)$ & $1(4)$ \\
\hline Retired & $21(57)$ & $12(52)$ \\
\hline Part-time and retired & $1(3)$ & $0(0)$ \\
\hline Unpaid work and retired & $0(0)$ & $1(4)$ \\
\hline \multicolumn{3}{|l|}{ Previous cardiac event, n (\%) } \\
\hline IHD (Ischaemic Heart Disease) & $7(19)$ & $1(4)$ \\
\hline Angina & $9(24)$ & $6(26)$ \\
\hline $\mathrm{PCl}$ & $6(16)$ & $4(17)$ \\
\hline Cardiac arrest & $5(14)$ & $2(9)$ \\
\hline Other & $10(27)$ & $10(44)$ \\
\hline \multicolumn{3}{|l|}{ Medication, n (\%) } \\
\hline Beta blockers & $33(89)$ & $18(78)$ \\
\hline $\begin{array}{l}\text { ACE (Angiotensin Converting } \\
\text { Enzyme) inhibitors }\end{array}$ & $32(87)$ & $19(83)$ \\
\hline GTN (Glyceryl Trinitrate) spray & $29(78)$ & $20(87)$ \\
\hline Anticoagulants & $19(51)$ & $11(48)$ \\
\hline Aspirin & $35(95)$ & $21(91)$ \\
\hline Statins & $35(95)$ & $21(91)$ \\
\hline Diuretics & $9(24)$ & $2(9)$ \\
\hline Calcium channel blocker & $4(11)$ & $5(22)$ \\
\hline Antiarrhythmic & $6(16)$ & $16(70)$ \\
\hline
\end{tabular}

BMI, body mass index;GTN, Glyceryl trinitrate; IHD, Ischeamic heart disease; $\mathrm{PCl}$, percutaneous coronary intervention.

flow of eligibility, screening, randomisation and follow-up in the study. The main reason for exclusion to the study was that patients did not meet the inclusion criteria, $\mathrm{n}=442$ (ie, no confirmed diagnosis of CHD, completed $\mathrm{CR}$ in the last 12 months, comorbidities/contraindications to exercise or not web literate). Of those eligible to be randomised, $\mathrm{n}=60$ or $26 \%$ were willing to take part in the trial. Tables 1 and 2 show the baseline characteristics and clinical outcomes of the two groups. The groups appear well matched at baseline though no statistical tests were performed to confirm this.

More patients dropped out/were lost to follow-up from the web intervention group $(n=7)$ compared with four in the control group by 6 months.

Retention rates in the trial were excellent: overall 54 patients attended the 8-week assessment (90\%; 95\% CI $79 \%$ to $96 \%$ ) and 49 patients attended the 6-month assessment ( $82 \%$; $95 \%$ CI $70 \%$ to $90 \%)$.

There were two adverse events in the web group and four in the control group-but all were deemed unrelated to the study procedures and interventions. At 8 weeks, four patients in the web group and one control patient reported at least one episode of angina in their symptom diaries. These episodes were relieved with glyceryl trinitrate spray and/or rest.

The most fruitful method of recruitment was to capture patients at the point of declining rehabilitation in a one-to-one assessment ( $>80 \%$ of those recruited) compared with retrospectively contacting those who had declined or dropped out of a programme previously.

table 3shows the change within groups for the clinical outcomes at 8 weeks and 6 months. The change in the MacNew total score at 6 months met suggested the minimum clinical important difference of $0.5^{41}$ for this outcome in the web group.

It was feasible to measure costs (health and social care resource use and patientborne costs) and outcomes (including health utility and return to normal work or other activity) using the Resource Use Questionnaire designed for this study-see here: http://www.dirum. org/instruments/details/104. The overall completion of this questionnaire was $90 \%$ across both groups at 6 months. In future work, both costs and outcomes will be analysed and reported using standard national Health Technology Assessment Framework standards. ${ }^{42}$

Web usage statistics are shown in figure 2A-C. Patients were able to double their exercise time (in minutes) from baseline to 8 weeks and this was maintained at the

Table 2 Clinical outcome measures at baseline, 8-weeks and 6-months in both groups. Results are presented as mean (SD)

\begin{tabular}{|c|c|c|c|c|c|c|}
\hline & \multicolumn{2}{|l|}{ Baseline } & \multicolumn{2}{|l|}{8 weeks } & \multicolumn{2}{|l|}{6 months } \\
\hline & Web & Con & Web & Con & Web & Con \\
\hline MacNew overall score & $5.9(1.0)$ & $6.0(0.8)$ & $6.2(0.7)$ & $6.2(0.6)$ & $6.5(0.5)$ & $6.2(0.6)$ \\
\hline ISWT (m) & $437.6(153.6)$ & $458.0(153.6)$ & $479.0(180.1)$ & $492.0(167.9)$ & $491.3(192)$ & $564.7(152.9)$ \\
\hline HADS Anxiety Score & $3.9(3.2)$ & $4.0(2.7)$ & $3.4(3.6)$ & $4.8(3.6)$ & $3.0(3.3)$ & $3.8(3.0)$ \\
\hline HADS Depression Score & $2.7(2.7)$ & $2.5(2.6)$ & $1.7(2.1)$ & $2.4(2.2)$ & $1.5(1.4)$ & $2.4(2.5)$ \\
\hline General Self-Efficacy Scale score & $33.6(4.3)$ & $35.4(4.0)$ & $35.2(3.5)$ & $35.3(4.8)$ & $35.8(3.6)$ & $35.7(4.2)$ \\
\hline
\end{tabular}

Results are presented as mean (SD).

HADS, Hospital Anxiety and Depression Scale;ISWT, incremental shuttle walking test. 
Table 3 Changes in clinical outcome measures at 8 weeks and 6 months in both groups

\begin{tabular}{|c|c|c|c|c|}
\hline & \multicolumn{2}{|l|}{8 weeks } & \multicolumn{2}{|l|}{6 months } \\
\hline & Web & Control & Web & Control \\
\hline MacNew overall & & & & \\
\hline score & $0.3(1.0)$ & $0.2(0.8)$ & $0.5(1.1)$ & $0.2(0.7)$ \\
\hline ISWT (m) & $45.5(57.0)$ & $50.0(76.9)$ & $52.9(76.8)$ & 85.9 (115.2) \\
\hline $\begin{array}{l}\text { HADS Anxiety } \\
\text { Score }\end{array}$ & $-0.3(3.0)$ & $0.7(3.1)$ & $-0.4(3.3)$ & $-0.2(2.8)$ \\
\hline $\begin{array}{l}\text { HADS } \\
\text { Depression } \\
\text { Score }\end{array}$ & $-0.3(3.0)$ & $0.7(3.1)$ & $-0.8(2.6)$ & $0.1(1.6)$ \\
\hline $\begin{array}{l}\text { General Self- } \\
\text { Efficacy Scale } \\
\text { score }\end{array}$ & $1.5(4.1)$ & $-0.1(2.9)$ & $2.1(5.1)$ & $-0.3(1.6)$ \\
\hline
\end{tabular}

Results are presented as mean (SD).

HADS, Hospital Anxiety and Depression Scale;ISWT, incremental shuttle walking test.

6-month assessment. The average number of log-ins was three times per week at the 8-week mark and twice a week at 6 months. Phone calls and emails from patients to staff were low and patients did not use the group forum. Twenty-nine (of the 37 participants) had completed the web programme at 6 months $(78 \%)$ and some were still working their way through the programme.
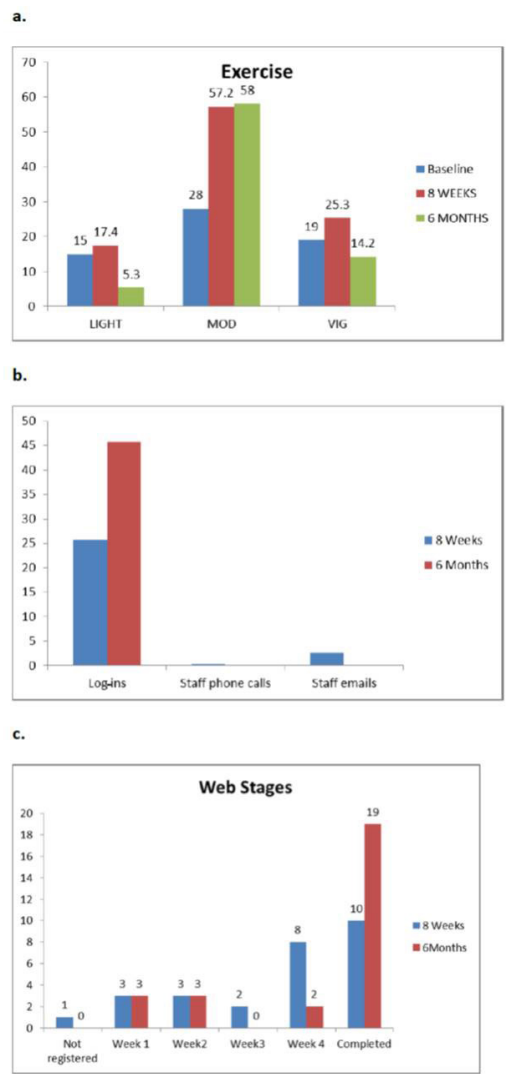

Figure 2 Web usage statistics. (A) Average minutes of exercise logged per week. (B) Average number of log-ins, phone calls and emails. (C) Completion of web stages.

\section{DISCUSSION}

CR is a highly effective intervention in the management of patients with CHD. ${ }^{5}$ Despite its numerous benefits, it is an underused treatment, with around only half of eligible patients in the UK and around 30\% in Europe accessing a programme. ${ }^{12} 43$ Alternative or more flexible ways of delivering CR therefore ought to be considered.

The data from this study show that a web-based CR programme ('ACTIVATE YOUR HEART') has the potential to be an acceptable way to increase the provision of CR for those unable (or unwilling) to attend a conventional programme. If alternative forms of CR allow more patients to access a service, this in turn could reduce the risk of future cardiac events for those able to attend a programme.

Of those who were eligible, a quarter agreed to participate. For future studies, we may need to review the inclusion criteria to allow those with more complex needs to access the web programme (including those with low shuttle walk test performance or high levels of anxiety or depression). Also, we expect that over time, the numbers of patients who are web literate will increase. This would be in line with the recent internet use statistics revealing that internet use in those aged 65 years and over is catching up with the younger age groups. ${ }^{22}$ Furthermore, we are aware that the NHS priorities around the use of technology in healthcare are changing and we would expect the capacity for digital health interventions to continue to grow. The NHS has pledged in its 5-year plan to 'train our staff so that they are able to support those who are unable or unwilling to use new technologies. ${ }^{, 44}$

We were encouraged by the high levels of engagement with the web programme, as measured by numbers of log-ins, exercise sessions logged and that $78 \%$ had completed the programme at 6 months (with others still working their way through the programme). It was perhaps surprising that patients took longer than the anticipated 8 weeks to complete the online programme. However, patients had access to the "ACTIVATE YOUR HEART' programme for 1 year, therefore the programme can be completed at the patients' own pace. Furthermore, access to the programme for this protracted period has the potential to improve maintenance, though we did not measure long-term follow-up of outcomes as part of this study. Interestingly, patients required minimal support from healthcare staff in terms of phone calls and emails. As this is the only part of web-based CR programme where costs increase with increasing numbers of participants (increased staff time); this suggests that the costs with increasing numbers will remain low. We were able to identify the best method of recruitment in this feasibility study. This was to approach patients prospectively at the point of declining rehabilitation in a one-to-one assessment (>80\% of those recruited) as opposed to retrospectively contacting those who had declined or dropped out of a programme previously. It may be that uptake at this stage was also influenced by the healthcare 
professional introducing the research study (ie, the clinical rehabilitation team and not the research team). We would use this recruitment strategy going forward to a full trial. However, we should not limit the offer of web-based rehabilitation to only those who decline a conventional, class-based programme. Last year, 65344 eligible patients missed out on a life-saving intervention that also improves quality of life. ${ }^{12} \mathrm{CR}$ ought to be a full menu with genuine choice and resources that support patient preference. Web-based rehabilitation is one of the innovations required to future proof CR.

Furthermore, it was feasible to collect all clinical, non-clinical and health utility outcomes in this trial. Finally, there was excellent completion of all study outcomes and procedures, with $82 \%$ of individuals attending all three assessment visits.

While this feasibility study was not powered to test clinical effectiveness of the web programme, we are encouraged by the clinically worthwhile gains shown in the MacNew Quality of Life Questionnaire in the web group and some small positive signals in the other outcome measures. Overall, we were able to show that the web-based CR programme was safe (low adverse events and attrition unrelated to the study intervention) and could secure improvements associated with conventional CR. Mood (anxiety and depression) and self-efficacy did not really improve in either group, though it is important to note a potential floor effect since the groups both had low levels of anxiety and depression and high self-efficacy scores at the programme's start, reducing scope for change. We did not anticipate the large change in the ISWT of the control group at 6 months ( $86 \mathrm{~m}$ vs $53 \mathrm{~m}$ in the web group), and are unsure of the reasons for this change. It may be argued that the mere act of performing an outcome measure may influence the subsequent outcome. In other words, the performance of an ISWT in itself could be considered an intervention and have an effect on the patients' confidence to complete that test. ${ }^{45}{ }^{46}$ However, as stated previously, the self-efficacy scores (an indicator of confidence) did not improve in either group. In a full-scale trial, it may be appropriate to perform a sensitivity analysis to examine the extent to which results are 'affected by changes in methods, models, values of unmeasured variables, or assumptions. ${ }^{47}$

\section{CONCLUSION}

This feasibility study of web-based CR versus usual care has provided us early signs of patient benefit and produced useful information about how best to recruit to a definitive trial. We have been encouraged by some promising outcomes and the data suggest feasibility for a full-scale trial. There is the potential for a trial looking at the effectiveness of the web-based programme in decliners. There is also the scope to evaluate web-based CR as part of a full menu of options.

This intervention has the opportunity to increase access to CR for patients who would otherwise not attend. Or to be an alternative mode of CR delivery in a full, choicebased CR menu. In turn, this could reduce the risk of future cardiac events and therefore be cost saving .

\section{Author affiliations}

${ }^{1}$ Centre for Exercise and Rehabilitation Science (CERS), NIHR Leicester Biomedical Research Centre (BRC)- Respiratory, University Hospitals of Leicester NHS Trust, Leicester, UK

${ }^{2}$ Faculty of Medicine and Health Sciences, University of Nottingham, Nottingham, UK

${ }^{3}$ Department of Neuroscience, Psychology and Behaviour, University of Leicester, Leicester, UK

${ }^{4}$ Institute of Applied Health Research, University of Birmingham, Birmingham, UK

${ }^{5}$ Faculty of Health and Life Sciences, Coventry University, Coventry, UK

${ }^{6}$ Health Sciences, University of York, York, UK

${ }^{7}$ Centre for Technology Enabled Health Research, Coventry University, Coventry, UK ${ }^{8}$ Medical Sciences Division, University of Oxford, Oxford, UK

${ }^{9}$ Department of Infection, Immunity and Inflammation, University of Leicester, Leicester, UK

Acknowledgements We thank the Cardiac rehabilitation nurses and therapists in Leicester for screening, recruitment, assessments and delivering the intervention: Chris Brough, Sally Schreder, Champa Patel, Lynda Barnes, Amye Watt, Tracy Elton, Michal Hardy, John Ormonde, Lorraine Voisey, Kirsten Gregory, Prabha Rufus, Celia Bloor and Ruth Nelson. Cardiac rehabilitation nurses and therapists in Lincoln for screening, recruitment, assessments and delivering the intervention: Charlotte Martin, Amanda Griffiths and Andrew Hall. Website development: HARK2. Data entry support: Mark Orme (Leicester BRC). Statistical analysis and advice: Nishal Bhupendra Jaicim and Cassandra Brookes (Leicester Clinical Trials Unit). Health utility feasibility reporting: Amir Khan (Coventry University). Qualitative interviews (will be reported elsewhere): Noelle Robertson and Jerri Bryant (University of Leicester).

Contributors LHW conducted the work, analysed the data and reported the work described in the article. NG conducted the work, managed the web usage data and helped redraft the work described in the article. RD, KJ, TM, GF, PD and JP planned the work and helped redraft the work described in the article. NR planned the work led the qualitative analysis and helped redraft the work described in the article. AS planned the work, led the health utility feasibility work and helped redraft the work described in the article. SS planned the work, helped redraft the work described in the article and is responsible for the overall content as guarantor.

Funding This paper presents independent research funded by the National Institute for Health Research (NIHR) under its Research for Patient Benefit (RfPB) Programme (grant reference number PB-PG-1013-32059). The work was also supported by the NIHR Leicester Biomedical Research Centre-Respiratory. LHW and SS are supported by NIHR CLAHRC East Midlands. KJ and TM are funded by the NIHR CLAHRC West Midlands. JP is supported by NIHR CLAHRC Oxford at Oxford Health NHS Foundation Trust.

Disclaimer The views expressed are those of the authors and not necessarily those of the NHS, the NIHR or the Department of Health.

Competing interests None declared.

Patient consent Not required.

Ethics approval NRES Committee East Midlands-Leicester (ref: 15/EM/0291).

Provenance and peer review Not commissioned; externally peer reviewed.

Data sharing statement Unpublished qualitative and health economic data are held by the authors-these will be published in subsequent manuscripts.

Open access This is an open access article distributed in accordance with the Creative Commons Attribution Non Commercial (CC BY 4.0) license, which permits others to distribute, remix, adapt, build upon this work non-commercially, and license their derivative works on different terms, provided the original work is properly cited and the use is non-commercial. See: http://creativecommons.org/licenses/by/4.0

\section{REFERENCES}

1. NHS Improvement, 2013. Making the case forcardiac rehabilitation:modelling potential impacton readmissions. Available from: www.natcansat.nhs.uk/dlhandler.ash $x ? d=$ pubs\&f $=$ Case for CR.pdf [Accessed Jan 2018]. 
2. Luengo-Fernández R, Leal J, Gray A, et al. Cost of cardiovascular diseases in the United Kingdom. Heart 2006;92:1384-9.

3. EHN, 2017. European cardiovascular disease statistics. Available from: http://www.ehnheart.org/cvd-statistics/cvd-statistics-2017. html [accessed Jan 2018].

4. NICE, 2013. CR service commissioning guide, implementing NICE guidance. Available from: http://www.nice.org.uk/media/49E/45/Card iacRehabilitationCommissioningGuide.pdf [accessed Jan 2018].

5. Anderson L, Oldridge N, Thompson DR, et al. Exercise-based cardiac rehabilitation for coronary heart disease. Cochrane Database Syst Rev 2016:CD001800.

6. Kennedy MD, Haykowsky M, Daub B, et al. Effects of a comprehensive cardiac rehabilitation program on quality of life and exercise tolerance in women: A retrospective analysis. Curr Control Trials Cardiovasc Med 2003;4:1.

7. , NICE, 2010. Chronic heart failure in adults: management. NICE Clinical guideline [CG108]. Available from: http://libdoc.who.int/trs/ WHO_TRS_831.pdf [accessed Jan 2018].

8. NICE, 2013. Myocardial infarction: cardiac rehabilitation and prevention of further cardiovascular disease. NICE Clinical guideline [CG172]. Available from: https://www.nice.org.uk/guidance/cg172 [accessed Jan 2018].

9. NICE, 2013. Unstable angina and NSTEMI: early management. NICE Clinical guideline [CG94]. Available from: https://www.nice.org.uk/ guidance/cg94 [accessed Jan 2018].

10. NICE, 2010. Chronic heart failure in adults: management. NICE Clinical guideline [CG108]. Available from: https://www.nice.org.uk/ guidance/cg108 [accessed Jan 2018]

11. DoH, 2013. Cardiovascular Disease Outcomes Strategy: Improving outcomes for people with or at risk of cardiovascular disease. Available from: https://www.gov.uk/government/publications/ improving-cardiovascular-disease-outcomes-strategy [accessed Jan 2018].

12. BHF, 2017. The national audit of cardiac rehabilitation annual statistical report. Available from: https://www.bhf.org.uk/ publications/statistics/national-audit-of-cardiac-rehabilitationannual-statistical-report-2017 [accessed Mar 2018].

13. O'Driscoll JM, Shave R, Cushion CJ. A National Health Service Hospital's cardiac rehabilitation programme: a qualitative analysis of provision. J Clin Nurs 2007;16:1908-18.

14. De Vos C, Li X, Van Vlaenderen I, et al. Participating or not in a cardiac rehabilitation programme: factors influencing a patient's decision. Eur J Prev Cardiol 2013;20:341-8.

15. McKee G, Biddle M, O' Donnell S, et al. Cardiac rehabilitation after myocardial infarction: what influences patients' intentions to attend? Eur J Cardiovasc Nurs 2014;13:329-37.

16. Neubeck L, Freedman SB, Clark AM, et al. Participating in cardiac rehabilitation: a systematic review and meta-synthesis of qualitative data. Eur J Prev Cardiol 2012;19:494-503.

17. Dalal HM, Doherty $P$, Taylor RS. Cardiac rehabilitation: clinical review. BMJ 2015;351:h5000.

18. Lewin B, Robertson IH, Cay EL, et al. Effects of self-help postmyocardial-infarction rehabilitation on psychological adjustment and use of health services. Lancet 1992;339:1036-40.

19. Lewin RJ, Furze G, Robinson J, et al. A randomised controlled trial of a self-management plan for patients with newly diagnosed angina. Br J Gen Pract 2002;52:194-201.

20. Grace SL, McDonald J, Fishman D, et al. Patient preferences for home-based versus hospital-based cardiac rehabilitation. $J$ Cardiopulm Rehabil 2005;25:24-9.

21. Harrison AS, Doherty P. Does the mode of delivery in Cardiac Rehabilitation determine the extent of psychosocial health outcomes? Int J Cardiol 2018;255:136-9.

22. ONS, 2017. Statistical bulletin: Internet users in the UK. Available from: https://www.ons.gov.uk/businessindustryandtrade/itandinterne tindustry/bulletins/internetusers/ [accessed Jan 2018]

23. Lindsay S, Smith S, Bellaby $\mathrm{P}$, et al. The health impact of an online heart disease support group: a comparison of moderated versus unmoderated support. Health Educ Res 2009;24:646-54.

24. Reid RD, Morrin LI, Beaton LJ, et al. Randomized trial of an internetbased computer-tailored expert system for physical activity in patients with heart disease. Eur J Prev Cardiol 2012;19:1357-64.

25. Southard BH, Southard DR, Nuckolls J. Clinical trial of an Internetbased case management system for secondary prevention of heart disease. J Cardiopulm Rehabil 2003;23:341-8.
26. Vernooij JW, Kaasjager HA, van der Graaf Y, et al. Internet based vascular risk factor management for patients with clinically manifest vascular disease: randomised controlled trial. BMJ 2012;344:e3750.

27. DoH, 2012. Measuring outcomes in the Department of Health Commissioning Pack for Cardiac Rehabilitation: final evaluation report. Available from: http://www.cardiacrehabilitation.org.uk/docs/ NACR_NHS_Improvement_audit.pdf [accessed Jan 2018].

28. Devi R, Singh SJ, Powell J, et al. Internet-based interventions for the secondary prevention of coronary heart disease. Cochrane Database Syst Rev 2015;(12):CD009386.

29. Devi R, Powell J, Singh S. Web-based cardiac rehabilitation programme for angina patients in primary care - a randomised controlled Trial. Journal of Medical Internet Research 2014;16:e186.

30. Brough C, Boyce S, Houchen-Wolloff L, et al. Evaluating the interactive web-based program, activate your heart, for cardiac rehabilitation patients: a pilot study. J Med Internet Res 2014;16:e242

31. Steventon A, Ariti C, Fisher E, et al. Effect of telehealth on hospital utilisation and mortality in routine clinical practice: a matched control cohort study in an early adopter site. BMJ Open 2016;6:e009221.

32. Morton K, Dennison L, May C, et al. Using digital interventions for self-management of chronic physical health conditions: a metaethnography review of published studies. Patient Educ Couns 2017; 100:616-35.

33. Madden M, Furze G, Lewin RJ. Complexities of patient choice in cardiac rehabilitation: qualitative findings. J Adv Nurs 2011;67:540-9.

34. BACPR, 2017. BACPR_Standards_and_Core_Components. Available from: http://www.bacpr.com/resources/BACPR Standards_and_Core_Components_2017.pdf [accessed Jan 2018]

35. Zigmond AS, Snaith RP. The hospital anxiety and depression scale. Acta Psychiatr Scand 1983;67:361-70.

36. Singh SJ, Morgan MD, Scott S, et al. Development of a shuttle walking test of disability in patients with chronic airways obstruction. Thorax 1992;47:1019-24.

37. Oldridge N, Guyatt G, Jones N, et al. Effects on quality of life with comprehensive rehabilitation after acute myocardial infarction. Am J Cardiol 1991;67:1084-9.

38. Schwarzer R, Jerusalem M. Generalized self-efficacy scale. In: Weinman J, Wright S, Johnston M, Measures in health psychology: a user's portfolio. Causal and control beliefs. Windsor, UK: NFERNELSON, 1995:35-7.

39. Lancaster GA, Dodd S, Williamson PR. Design and analysis of pilot studies: recommendations for good practice. J Eval Clin Pract 2004;10:307-12.

40. Billingham SA, Whitehead AL, Julious SA. An audit of sample sizes for pilot and feasibility trials being undertaken in the United Kingdom registered in the United Kingdom clinical research network database. BMC Med Res Methodol 2013;13:104.

41. Dixon T, Lim LL, Oldridge NB. The MacNew heart disease healthrelated quality of life instrument: reference data for users. Qual Life Res 2002;11:173-83.

42. Husereau Det al. Consolidated Health Economic Evaluation Reporting Standards (CHEERS)--explanation and elaboration: a report of the ISPOR health economic evaluation publication guidelines good reporting practices task force. Value Health 2013;16:231-50.

43. Bjarnason-Wehrens $B$, McGee H. Cardiac rehabilitation in Europe: results from the European cardiac REHabilitationABILITATION inventoryINVENTORY Survey. Eur J Cardiovasc Prev Rehabil 2010;17:410-8.

44. NHS England, 2018. Five Year Forward View. Available from: https:// www.england.nhs.uk/wp-content/uploads/2014/10/5yfv-web.pdf [accessed Jan 2018]

45. Godin G, Bélanger-Gravel A, Amireault S, et al. The effect of mere-measurement of cognitions on physical activity behavior: a randomized controlled trial among overweight and obese individuals. Int J Behav Nutr Phys Act 2011;8:2

46. Kanabar P, Ruksenaite J, Houchen-Wolloff L, et al. Shuttle walk tests: are they just an outcome measure? Thorax 2017;72

47. Thabane L, Mbuagbaw L, Zhang S, et al. A tutorial on sensitivity analyses in clinical trials: the what, why, when and how. BMC Med Res Methodol 2013;13:92. 